\title{
S-1
}

\section{Measurement of gas-phase hydroperoxides by chemical ionization mass spectrometry (CIMS)}

John D. Crounse*, Karena A. McKinney ${ }^{+\&}$, Alan J. Kwan ${ }^{\#}$, and Paul O. Wennberg ${ }^{+\#}$

*Div. of Chemistry and Chemical Engineering, California Institute of Technology

${ }^{+}$Div. of Geological and Planetary Sciences, California Institute of Technology

\# Div. of Engineering and Applied Science, California Institute of Technology

${ }^{\&}$ Currently with Dept. of Chemistry, Amherst College

Abstract: As supporting information we present table S-1 containing information regarding the average sensitivities and backgrounds for the CIMS technique at several water levels as well as figure $\mathrm{S}-1$ showing the ratio of the URI $\left(\mathrm{H}_{2} \mathrm{O}_{2}\right) / \mathrm{CIT}\left(\mathrm{H}_{2} \mathrm{O}_{2}\right)$ measurements from INTEX-NA as a function of water mixing ratio. 
Table S-1: Typical sensitivities and backgrounds for several hydroperoxides measured by the Caltech CIMS at several water levels.

\begin{tabular}{|c|c|c|c|c|c|c|}
\hline $\begin{array}{l}\text { Ambient } \\
\text { [H2O] } \\
\text { (ppmv) }\end{array}$ & $\begin{array}{l}\mathrm{H}_{2} \mathrm{O}_{2} \\
\text { sensitivity } \\
\left(\text { cts s s}^{-1}\right. \\
\left.\text { pptv }^{-1}\right)\end{array}$ & $\begin{array}{l}\text { PAA } \\
\text { sensitivity } \\
\left(\text { cts s }^{-1}\right. \\
\left.\text { pptv }^{-1}\right)\end{array}$ & $\begin{array}{l}\text { MHP } \\
\text { sensitivity } \\
\left(\operatorname{cts~s}^{-1}\right. \\
\left.\text { pptv }^{-1}\right)\end{array}$ & $\begin{array}{l}\mathrm{H}_{2} \mathrm{O}_{2} \\
\text { background } \\
\left(\text { cts s}^{-1}\right)\end{array}$ & $\begin{array}{l}\text { PAA } \\
\text { background } \\
\left(\text { cts } s^{-1}\right)\end{array}$ & $\begin{array}{l}\text { MHP } \\
\text { background } \\
\left(\operatorname{cts~s}^{-1}\right)\end{array}$ \\
\hline $1 \times 10^{2}$ & 15 & 15 & 12 & 120 & 80 & 640 \\
\hline $1 \times 10^{3}$ & 25 & 17 & 4 & 400 & 120 & 1000 \\
\hline $1 \times 10^{4}$ & 4 & 9 & 0.1 & 1000 & 200 & 1500 \\
\hline
\end{tabular}


Figure S-1: Ratio of URI- $\mathrm{H}_{2} \mathrm{O}_{2} / \mathrm{CIT}-\mathrm{H}_{2} \mathrm{O}_{2}$ as a function of water. The dash-dot line is robust fit to data $(\mathrm{m}=0.00, \mathrm{~b}=1.07)$.

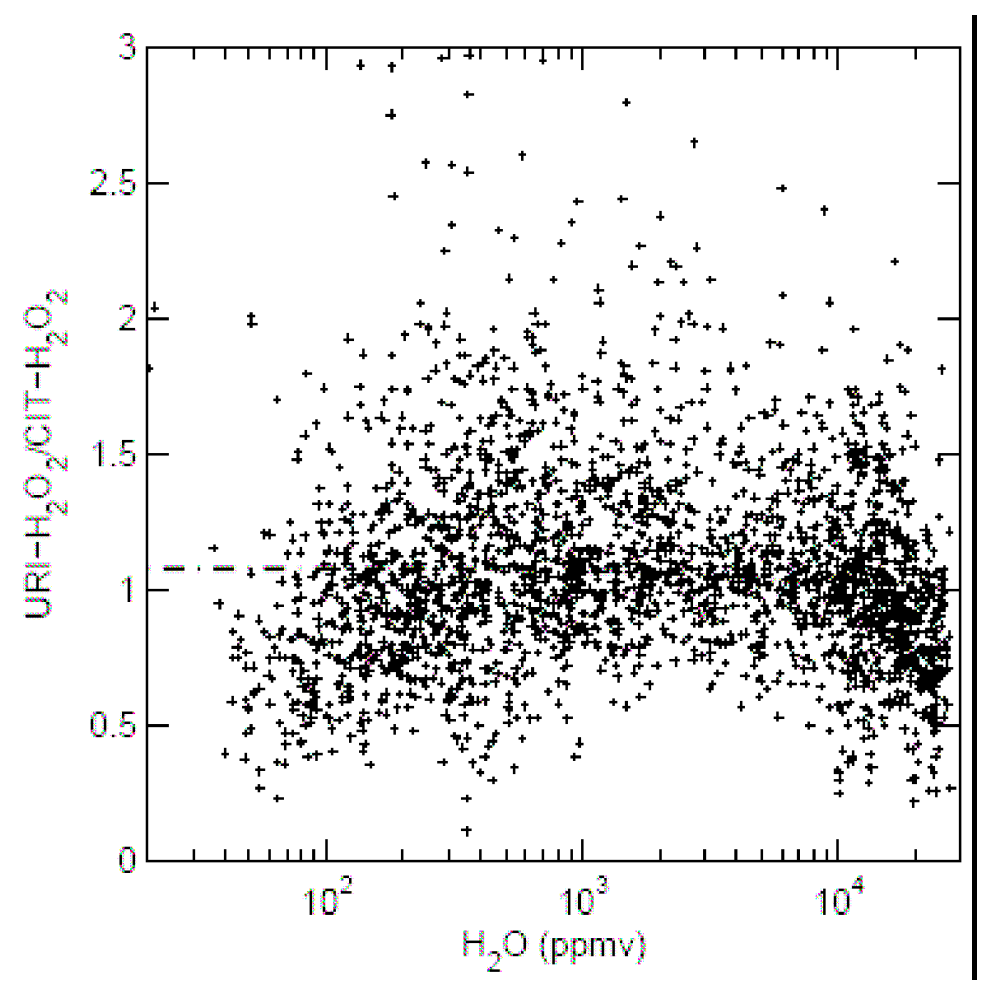

